\title{
Analyzing the Layout of China's Strategic Petroleum Reserve Base
}

\author{
Jianbo Yang, Qunyi Liu \\ Institute of mineral resources, CAGS, No.26 Baiwanzhuang Street, Xicheng District, Beijing \\ 100037, China;
}

Global mineral resources strategy research centre,CAGS. No.26 Baiwanzhuang Street, Xicheng

District, Beijing 100037, China

Keywords: Petroleum; Strategic reserve; Base layout

Abstract: With the development of China's economy, its dependence on foreign oil increases every year. Therefore, oil reserves play a vital role in ensuring China's energy security. The selection of a base site for the construction of strategic oil reserves is a priority. This study analyzes the status quo as well as future development trends for oil processing conditions, pipeline transportation conditions, consumption and production in the base radiation area, crude oil loading and unloading capacity of the port, reserve modes, and other factors. Preliminary planning of the spatial layout of the petroleum strategic reserve base is also detailed in this study. Strategic oil reserve bases can be positioned at the Pearl River Delta, the crude oil pipelines of Central and Southwest China and the large refineries and locations near the crude oil port terminals. Meanwhile, ground and underground reserve modes should be combined.

\section{Preface}

As a type of strategic material, petroleum plays a significant role in the development of the national economy. In 2015, China's dependence on foreign oil reached $60.6 \%$. Since the growth of domestic oil supply is weak, this external dependence will increase every year and oil supply security will become increasingly serious. Reserves, as the last defense line of China's oil security, are particularly important. In this study, the layout of the reserve base is analyzed.

\section{Factors influencing the base layout}

The layout of the national oil reserve base should follow the "safe, reliable, economic and efficient" principle and be characterized as high construction safety and reliability, low operation cost and fast oil injection and release from the reserve base. Therefore, site selection for the oil reserve base should focus on the oil processing conditions, pipeline transportation conditions, oil consumption and production in the base radiation area, crude oil loading and unloading capacity of the port, reserve mode and other factors.

\section{Oil processing conditions}

In recent years, with the rapid development of China's oil refining industry, the refining capacity has increased from 320 million t/a in 2005 to 702 million t/a in 2014. Oil refining industry clusters are mainly distributed in the Bohai Bay, Yangtze River Delta and Pearl River Delta. In 2014, 
the refining capacity of the Circum-Bohai Sea Region, the Yangtze River Delta and the Pearl River Delta accounted for $43.7 \%, 14.4 \%$ and $11.5 \%$ of the country's total refining capacity, respectively.

At present, China has formed a basic pattern dominated by the refineries of China Petroleum \& Chemical Corporation (Sinopec) and China National Petroleum Corporation (CNPC), supplemented by local refineries (Fig. 1). CNPC refineries are mainly distributed in Northeast and Northwest China, including nine refineries with a capacity of more than 10 million t/a. Sinopec refineries are mainly distributed in East and Central South China where in the refined oil consumption is highly concentrated, including 13 refineries with a capacity of more than 10 million t/a. Local refineries are mainly distributed in Shandong and Shanxi.

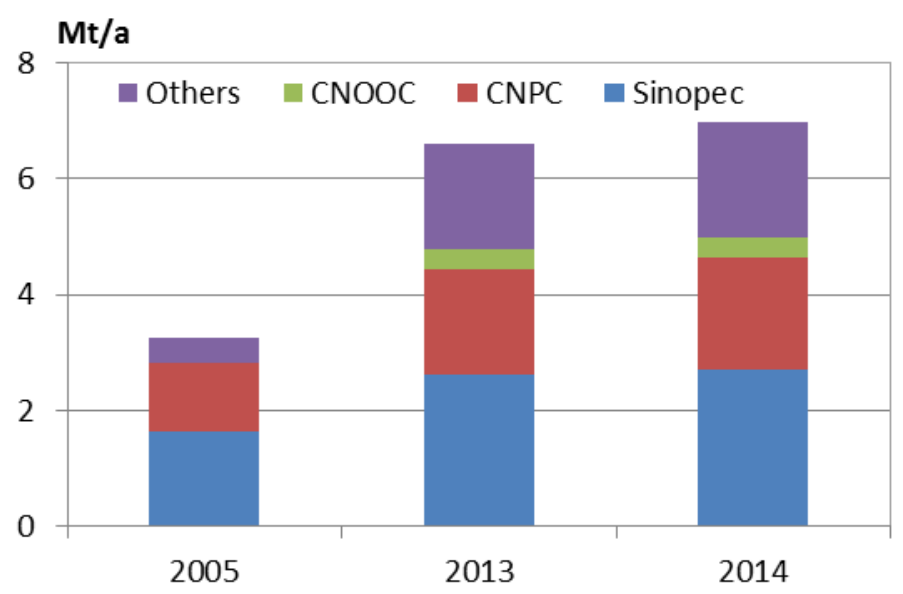

Fig. 1 Refining capacity of oil refineries in China in 2014

( Data sources : CNPC Economics\&Technology Research Institute )

Crude oil processing volume increased from 282 million tons in 2005 to 503 million tons in 2014 , with an average annual growth rate of 5.3\%; however, the average operating rate continued to decrease to $72 \%$ in 2014, significantly lower than the international average of $84 \%$ (Fig. 2).

In the future, the refinery construction will slow down. The increase will mainly originate from local refineries with access to crude oil import rights. The proportion of crude oil processing volume of the main state-owned refineries will further decrease. The crude oil processing capacity in 2020 is expected to be 590 million tons. 


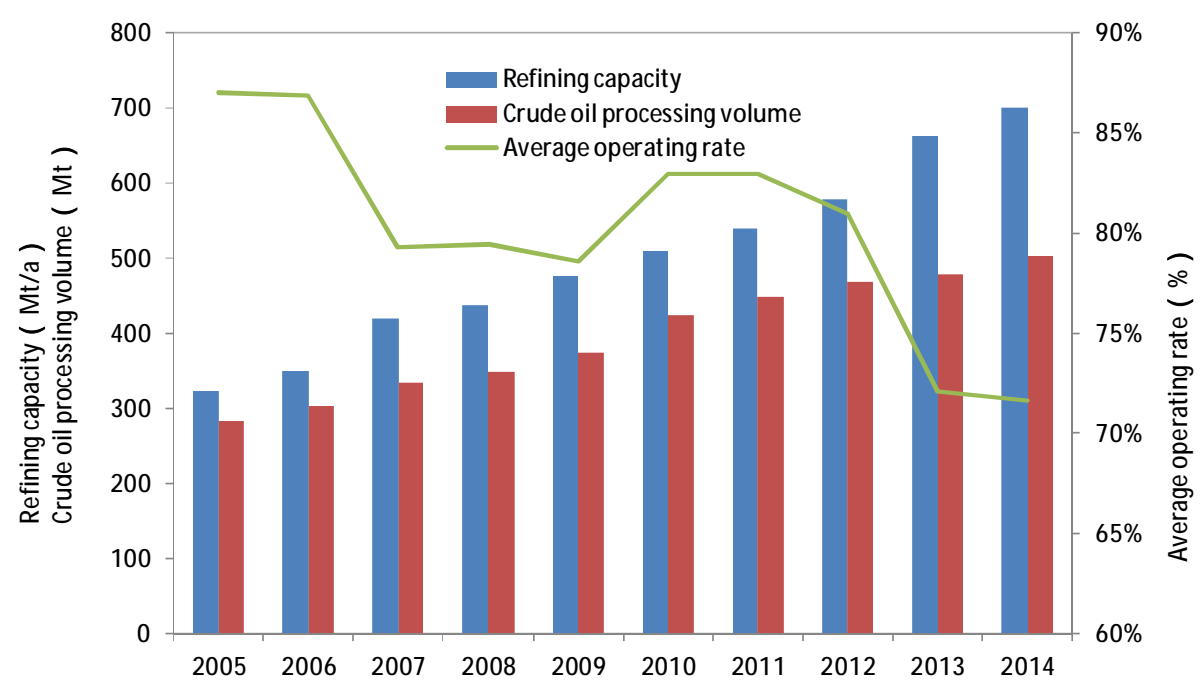

Fig. 2 Refining capacity and crude oil processing volume in China in 2005-2014

( Data sources : CNPC Economics\&Technology Research Institute )

\section{Pipeline construction}

China has formed a crude oil transportation network based on three major strategic energy channels. In 2014, China's crude oil pipeline was 27,000 km. The Sino-Russian crude oil pipeline in the channel of Northeast China is connected with the pipeline network of Northeast China. The Sino-Kazakhstan crude oil pipeline in the channel of Northwest China is connected with the pipeline of Western China. The channel of Southwest China is connected with the Sino-Myanmar oil and gas pipeline to avoid the Malacca Strait, reducing the risk of marine energy imports.

In the near future, the focus will be on domestic and imported crude oil supply to develop the western pipe network, improve the eastern pipe network, and adjust the northeast pipe network. In 2020 , the crude oil pipeline length will increase to $25,000 \mathrm{~km}$ with an oil delivery capacity of 380 million t/a. In 2030, the total length of the pipeline will reach $30,000 \mathrm{~km}$, with a pipeline capacity of 500 million t/a.

\section{Oil production}

China's crude oil production is mainly concentrated in the Heilongjiang and Shandong regions of Eastern China and Xinjiang, Shaanxi and other provinces (regions) of Western China. In 2014, the oil output in Heilongjiang was 40 million tons, accounting for $18.7 \%$ of China's total oil output. In Western China, due to increased investment in exploration and development in recent years, the oil output in Xinjiang increased significantly and was 28.75 million tons in 2014, accounting for $13.6 \%$ of China's total oil output.

In the future, it is difficult to increase oil production since most of the main oilfields in North and Northeast China are in the middle and later stages of exploitation. Western China and the oceans will become the new strategic areas for China's petroleum industry. However, since the oil 
price remains at low level, the growth rate of investment in development reduces. As a result, the future oil production growth will be limited and oil production will remain at 210-220 million tons.

\section{Oil consumption}

From 2001 to 2015, China's crude oil consumption continued to increase with a varying growth rate. In 2015, as the domestic oil consumption continued to be in low growth, China's apparent consumption of crude oil was 543 million tons, with an annual growth of $0.7 \%$.

In the future, although China's economic growth will slow down, passenger car ownership will continue to grow and new urbanization will advance. In this context, China's oil demand is expected to gradually increase and reach 590 million tons in 2020.

\section{Oil transportation and port conditions}

According to the National Plan for Coastal Port Layout, issued by the Ministry of Communications in 2007, large crude oil ports, such as Dalian, Tianjin, Qingdao, Yingkou and Tangshan, were formed in the coastal areas of Northern China. The crude oil transfer transport system was formed in the Yangtze River Delta, with Ningbo and Zhoushan as the main loading and unloading terminals and with Shanghai, Nanjing, Jiaxing and other ports along the Yangtze River as the endpoint. Quanzhou, Huizhou, Maoming, Zhanjiang and Yangpu are the foreign crude oil loading and unloading terminals and transfer transport systems located at the coastal area of South China. At the end of 2015, China had 73 crude oil berths with a capacity of above ten thousand tons, 133 refined oil berths with a capacity of above ten thousand tons and loading and unloading capacity of 530 million t/a. Large crude oil terminals with a capacity of above 100,000 tons have been constructed and put into operation, mainly concentrated in the Circum-Bohai Sea Region, with a loading and unloading capacity of 240 million t/a, accounting for $45.6 \%$.

In the future, the loading and unloading capacity of major crude oil transportation terminals in China will be limited and the modernization level will gradually improve on the basis of existing capacity. Their distribution will be basically in line with the present situation.

\section{Reserve conditions}

The cost of ground oil storage depots is high, around 110 to 131 US dollars/ton. In contrast, the oil storage cost of the coastal underground cavernin the Gulf of Mexico is only about 11 US dollars/ton. Therefore, the distribution of salt caverns or underground caves is also a factor affecting the site selection of oil reserve bases.

China's rock salt mine is mainly distributed in Jiangsu, Hubei, Jiangxi, Guangdong and other provinces. Salt caverns that have entered the feasibility study stage and pilot tests are currently mainly distributed in Jintan of Jiangsu, Yunying of Hubei, Pingdingshan of Henan, and Huai'an of Jiangsu. In the future, China may make large-scale use of salt caverns for underground cave oil reserves. 


\section{Layout of an oil reserve base}

In December 2015, the Ministry of Finance of the People's Republic of China issued a document, announcing that China's national oil reserve construction made significant progress. As of mid-2015, China built eight national oil reserve bases, including seven ground storage depots (i.e., the Zhoushan, Zhenhai, Dalian, Huangdao, Dushanzi, Lanzhou and Tianjin national oil reserve base) and one underground storage depot (i.e.,Huangdao water-tight underground oil tank). Reserve bases are mainly distributed in the eastern coast and the west of China, whereas central and southwest regions of China have no oil reserve bases.

The centralized reserve scheme characterized by "few sites and large scale" can be used for the distribution of China's crude oil reserves, this means reducing the amount of reserve bases and improving the reserve scale of each site. According to the abovementioned analysis of China's oil processing capacity, the distribution of the crude oil pipeline network and the oil loading and unloading capacity of ports, with comprehensive consideration of the Petrochemical Industry Layout Scheme and the " $13^{\text {th }}$ Five-Year Plan" of the petrochemical industry, the following suggestions on the site selection of China's oil reserve base are put forward (Fig. 3):

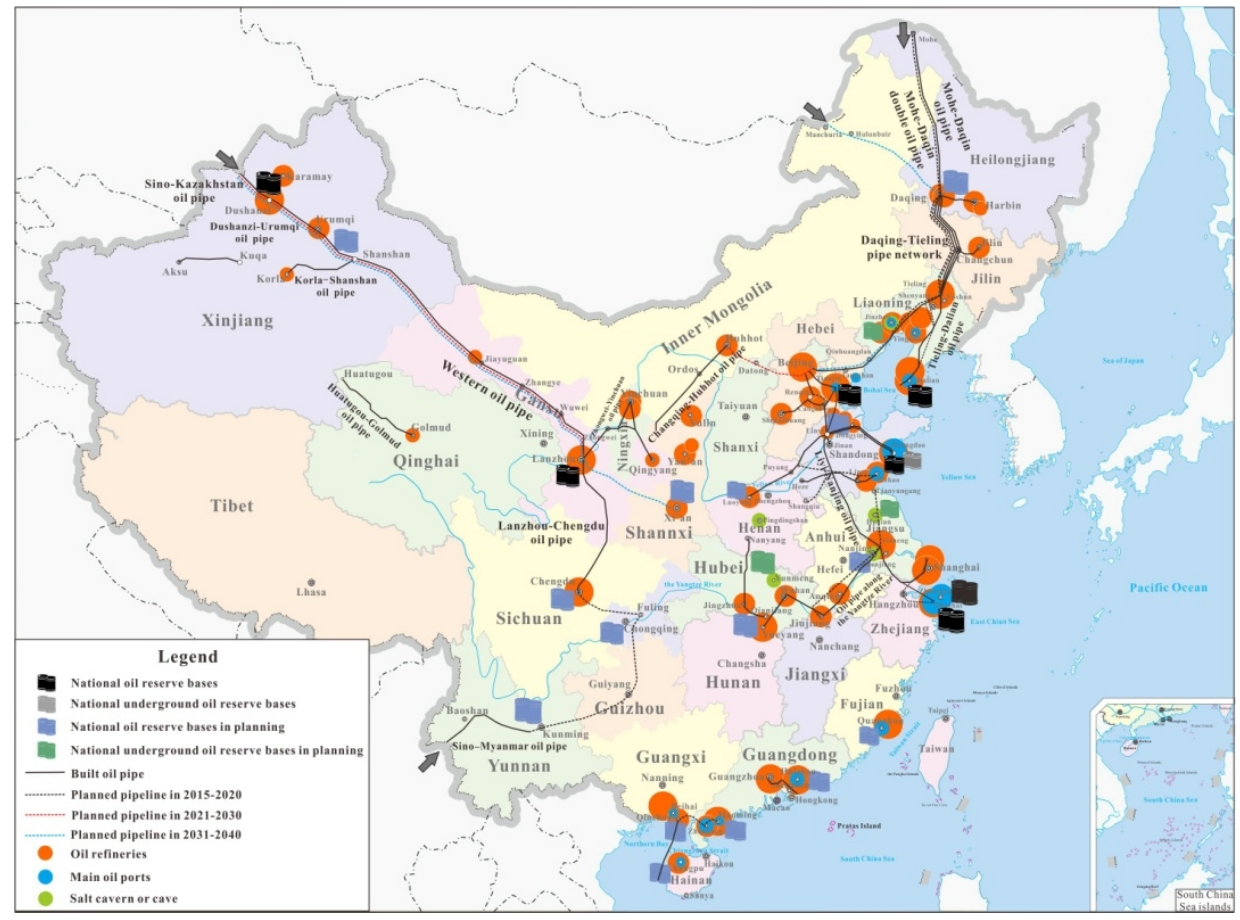

Fig. 3 Layout of oil reserve base

1) Northeast China (two crude oil reserve bases): To establish a crude oil reserve base in the southwest of Heilongjiang and lay out an underground oil reserve base in the southwest of Liaoning.

2) Northwest China: To establish a crude oil reserve base adjacent to the CNPC Urumqi Petrochemical Company along the crude oil pipeline of Western China.

3) Southwest China: To establish a crude oil reserve base in the Sichuan Province. 
4) North China: To establish a crude oil reserve base in Western Shandong.

5) East China: To establish an underground storage depot in the southern regions of Jiangsu.

6) South China: To lay out a crude oil reserve base in the southeast of Fujian, establish two crude oil reserve bases in the Pearl River Delta region and two crude oil reserve bases in coastal areas of Guangxi and Hainan.

7) Central China: To establish a crude oil reserve base in the vicinity of the pipeline along the Yangtze River in Hunan and Hubei and a crude oil reserve base along the Huangdao-Luoyang crude oil pipeline.

\section{Conclusion}

Based on the principles of high construction safety and reliability, low operation cost and fast oil injection and release to and from the reserve base, this paper makes a concise analysis of the status quo and future development trend of the oil processing conditions, oil pipeline transportation conditions, oil consumption and production in the base radiation area, crude oil loading and unloading capacity of the port, reserve mode and other factors. In addition, it also sets out a preliminary planning of the spatial layout of China's strategic oil reserve base in accordance with China's future petrochemical industry development planning. Strategic oil reserve bases can be positioned at the Pearl River Delta, the crude oil pipelines of Central and Southwest China and the large refineries and locations near the crude oil port terminals. The ground and underground reserve modes should be used in combination.

\section{References}

[1] Hongqiang Li, Limao Wang, "Index System for Selection of Strategic Petroleum Reserve Bases”, 2008,Vol. 30(4),565-561

[2] Qin Kun, “A study of China oil security and oil reserve base”, Shanghai,East China Normal University,2005

[3] Feng Ding, "The introduction of petroleum reserve in Japan,America, England, France and Germany", Land\&Resource,2005,Vol. (4),p50-51

[4] Chao Miao,Aiping Song, Faqian Gao,Xiaoan Guo, "China's refining industry today and the situation faced in 2014”, Sin-global energy, 2015, Vol. 20(7), p1-8.

[5] He Zhu, Yun Jin, “The development situation and future tendency of China's refining industry(Part 1)”, China Petroleum and Chemical Industry ,2015,Vol. (6),p6-9

[6] He Zhu,Yun Jin, “The development situation and future tendency of China's refining industry(Part 2)”, China Petroleum and Chemical Industry ,2015,Vol. (6),p10-13 
[7] Huajun Fan, Zhonghong Wang, "Characteristics and development trendency of oil and gas pipeline construction in Asia”, Petroleum Engineering Construction,2010,Vol.36(5),p6-9

[8] China National Petroleum Corporation, "Annual report of CNPC in 2015" , 2016-3-23,http://www.petrochina.com.cn/petrochina/rdxx/201603/d534a9ced50f49c7b7252d9c9d8 1853c/files/46be0b46fb2446488f8cb843b8ed9673.pdf

[9] Lemin Gu, "Historical review and future tendency of oil production in China", Acta Petrolei Sinica, 2016, Vol. 37(2), p280-288

[10] Hongbin, Dong Tong, "Present situation of port industry and its status in the national economy", Shangdong Social Sciences, 2014, Vol. (1), p144-149

[11] Haitao Pan, Ronghua Fu, "Port condition requirements for national strategic petroleum reserve base", Port Engineering Technology, 2003,Vol. (3),p14-16

[12] Jianying He, Dengqing Zhang, "Salt mine exploiting and petroleum reserve storage building”, China Foreign Energy, 2006,Vol.(3),p7-11 